\title{
QUANTITATIVE ASSESSMENT OF SEISMIC HAZARD FOR THE TERRITORY OF UZBEKISTAN ACCORDING TO THE ESTIMATED MAXIMUM GROUND OSCILLATION RATES AND THEIR SPECTRAL AMPLITUDES
}

\author{
T. U. Artikov, R. S. Ibragimov, T. L. Ibragimova, \\ K. I. Kuchkarov, M. A. Mirzaev \\ G.A. Mavlyanov Institute of Seismology, Academy of Sciences of the Republic of Uzbekistan, \\ Tashkent, Uzbekistan
}

\begin{abstract}
In the territory of Uzbekistan, seismic activity is high, and ensuring seismic safety of the population is among the most important problems for the country. Our study was focused on discovering relationships between the attenuation of the ground oscillation rates, their spectral amplitudes and the distances to the epicentres of the earthquakes of different energy levels, which took place in the region under study. An objective was to quantitatively assess the seismic hazard of the study area. We analyzed the velocity graphs of M 3.8-6.2 earthquakes that occurred in Uzbekistan and the neighbouring territories, and the recorded earthquake spectrum data. For the region under study, it is established that the attenuation of the ground oscillation rates and their spectral amplitudes depend on the distances. Taking into account the sizes of crustal earthquake foci, the spectra of ground oscillation rates were calculated for the near zone. Based on the established regional dependencies, the maximum ground oscillation rates and spectral velocity amplitudes were estimated, and seismic hazard probability for the territory of Uzbekistan was assessed. For several towns and cities of Uzbekistan, the highest predictable spectral amplitudes were determined, which, under given probability $\mathrm{P}$, will not be exceeded within the coming 50 years. The quantitative characteristics of seismic hazard can be converted to the indicators of seismic activity impacts, as required for calculating the seismic loads in earthquake-resistant engineering and construction projects.
\end{abstract}

Key words: soil oscillation rate; velocigram; the law of attenuation of the intensity of seismic effects; spectral amplitude; seismic impact; seismic hazard; seismic zoning

For citation: Artikov T.U., Ibragimov R.S., Ibragimova T.L., Kuchkarov K.I., Mirzaev M.A., 2018. Quantitative assessment of seismic hazard for the territory of Uzbekistan according to the estimated maximum ground oscillation rates and their spectral amplitudes. Geodynamics \& Tectonophysics 9 (4), 1173-1188. doi:10.5800/GT-2018-9-4-0389.

Для цитирования: Артиков Т.У., Ибрагимов Р.С., Ибрагимова Т.Л., Кучкаров К.И., Мирзаев М.А. Количественные характеристики сейсмической опасности территории Узбекистана в максимальных значениях скоростей колебаний грунта и в их спектральных амплитудах // Геодинамика и тектонофизика. 2018. Т. 9. №4. C. 1173-1188. doi:10.5800/GT-2018-9-4-0389. 


\title{
КОЛИЧЕСТВЕННЫЕ ХАРАКТЕРИСТИКИ СЕЙСМИЧЕСКОЙ ОПАСНОСТИ ТЕРРИТОРИИ УЗБЕКИСТАНА В МАКСИМАЛЬНЫХ ЗНАЧЕНИЯХ СКОРОСТЕЙ КОЛЕБАНИЙ ГРУНТА И В ИХ СПЕКТРАЛЬНЫХ АМПЛИТУДАХ
}

\author{
Т. У. Артиков, Р. С. Ибрагимов, Т. Л. Ибрагимова, \\ К. И. Кучкаров, М. А. Мирзаев
}

\begin{abstract}
Институт сейсмологии им. Г.А. Мавлянова Академии наук Республики Узбекистан, Ташкент, Узбекистан
\end{abstract}

\begin{abstract}
Аннотация: Территория Узбекистана характеризуется высоким уровнем сейсмической активности, и поэтому проблема обеспечения сейсмической безопасности населения республики весьма актуальна. Целью исследования является получение региональных зависимостей затухания амплитуд скоростей колебаний грунта и их спектральных составляющих с расстоянием для землетрясений различного энергетического уровня и построение на их основе количественных оценок сейсмической опасности исследуемой территории. Проведен анализ велосиграмм землетрясений с M=3.8-6.2, произошедших на территории Узбекистана и в прилегающих к нему областях, а также спектров записей этих землетрясений. Установлены региональные зависимости затухания скоростей колебаний грунта и их спектральных амплитуд с расстоянием. С учетом размеров очага корового землетрясения рассчитаны спектры скоростей колебаний грунта в ближней зоне. На основе установленных региональных зависимостей проведена вероятностная оценка сейсмической опасности территории Узбекистана в значениях максимальных скоростей колебаний грунта и в спектральных амплитудах скоростей. Для ряда населенных пунктов определены предельные значения спектральных амплитуд, которые с заданной вероятностью Р не будут превышены в течение 50 лет. Полученные количественные характеристики сейсмической опасности в инженерных показателях сейсмических воздействий необходимы для расчета сейсмических нагрузок при сейсмостойком строительстве.
\end{abstract}

Ключевые слова: скорость колебаний грунта; велосиграмма; закон затухания интенсивности сейсмических воздействий; спектральная амплитуда; сейсмическое воздействие; сейсмическая опасность; сейсмическое районирование

\section{1. ВВЕДЕНИЕ}

На территории Узбекистана и в сопредельных с ним регионах как за исторический период времени, так и на современном этапе неоднократно происходили землетрясения с магнитудой $\mathrm{M} \geq 7$ и интенсивностью сотрясений в эпицентре $\mathrm{I}_{0}=9-10$ баллов по шкале MSK-64, поэтому проблема обеспечения сейсмической безопасности территории республики весьма актуальна. В работе [Artikov et al., 2018] обсуждается методология количественной оценки сейсмической опасности, использованная при разработке новых карт общего сейсмического районирования территории Узбекистана ОСР-2017. В построенных картах сейсмическая опасность выражена в баллах макросейсмической шкалы и характеризуется расчетной интенсивностью сейсмического воздействия, которая с заданной вероятностью $(\mathrm{P}=0.90, \mathrm{P}=0.95, \mathrm{P}=0.98$ и $\mathrm{P}=0.99)$ не будет превышена в течение 50 лет.
Количественные характеристики сейсмической опасности в инженерных показателях сейсмических воздействий необходимы для расчета сейсмических нагрузок при сейсмостойком строительстве. Наибольшее распространение в странах ближнего и дальнего зарубежья к настоящему времени получили оценки сейсмической опасности, основанные на анализе записей ускорений колебаний грунта при землетрясениях [Akkar, Bommer, 2010; Artikov, Ibragimov, 2007; Artikov et al., 2012; Drennov et al., 2015; Lindholm et al., 2014; Ullah et al., 2015; Chernov, 1989; и $\partial p$.]. Районирование сейсмической опасности территории Узбекистана в значениях максимальных ускорений и в спектральных амплитудах ускорений колебаний грунта приведены в работах [Artikov, Ibragimov, 2007; Artikov et al., 2012; Chernov, 1989]. При построении очаговых спектров ускорений от землетрясений различного энергетического уровня и выявлении особенностей их трансформации с удалением от источника в этих работах ис- 
пользовались акселерограммы основных толчков и афтершоков Газлийских землетрясений 1976 и 1984 гг. с М=7.0-7.3, роя Папских землетрясений 1984 г., магнитуда максимального толчка которого составляла $\mathrm{M}=5.6$, а также цифровые записи ускорений колебаний грунта из европейского банка сильных движений.

В работах [Akkar, Bommer, 2010; Aptikaev, 2012; Chernov, 1989; u дp.] высказывается аргументированное мнение о том, что количественные характеристики интенсивности сейсмических воздействий, базирующиеся на интерпретации записей скоростей колебаний грунта, представляют не меньший научный и практический интерес для построения количественных оценок сейсмической опасности.

Накопленный к настоящему времени статистически представительный материал цифровых записей землетрясений различного энергетического уровня, произошедших на различных эпицентральных расстояниях от регистрирующих сейсмических станций, позволяет получить региональные зависимости затухания интенсивности сейсмических воздействий в значениях скоростей колебаний грунта и в их спектральных амплитудах и провести районирование сейсмической опасности исследуемой территории в этих показателях.

\section{2. ИСХОДНЫЕ СЕЙСМОЛОГИЧЕСКИЕ ДАННЫЕ И МЕТОДИКА ИХ АНАЛИЗА}

Региональной сетью сейсмических станций, функционирующей в настоящее время на территории Узбекистана, осуществляется регистрация землетрясений, основанная на цифровой записи скоростей колебаний грунта. На рисунке 1 показана действующая на территории республики сеть сейсмических станций и карта эпицентров инструментально зарегистрированных на территории Узбекистана и в сопредельных с ним областях землетрясений с магнитудой $\mathrm{M} \geq 3.5$ начиная с 1955 г. На этом же рисунке приведены активные разломы земной коры и выделенные на их основе сейсмогенерирующие зоны [Ibragimov et al., 2002].

В качестве основной характеристики для классификации землетрясений по величине в региональном каталоге используется энергетический класс землетрясений $K$. Переход от энергетического класса $K$ к локальной магнитуде $\mathrm{M}_{\mathrm{L}}$ (в дальнейшем тексте просто $M$ ), определяемой по горизонтальной составляющей поверхностных волн на короткопериодной аппаратуре, осуществлялся на основе соотношений [Mikhailova et al., 1999]:

$\mathrm{K}=1.8 \mathrm{M}+4.0(\mathrm{M}<5.5)$,

$$
\mathrm{K}=1.5 \mathrm{M}+5.6(\mathrm{M} \geq 5.5) .
$$

Для выявления закономерностей затухания амплитуд скоростей колебаний грунта и особенностей изменения спектрального состава сейсмических колебаний с удалением от источника было проанализировано свыше 500 велосиграмм и более 150 спектров записей скоростей колебаний грунта

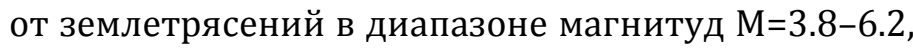
произошедших на эпицентральных расстояниях $\mathrm{R} \leq 500$ км от регистрирующих сейсмических станций.

На компоненте записи с наибольшей зарегистрированной амплитудой S-волны снимались значения максимальной амплитуды колебания, а с рассчитанных спектров скоростей колебаний грунта - спектральные амплитуды на периодах от $\mathrm{T}=0.05$ до $\mathrm{T}=2.5$ c.

На рисунке 2 для каждого из рассматриваемых периодов колебаний T приведены экспериментальные значения спектральных амплитуд скоростей колебаний грунта $\mathrm{S}_{\mathrm{T}}($ мкрн/c) на различных эпицентральных расстояниях R (км) от очага землетрясения и для землетрясений различного магнитудного уровня М показана линейная аппроксимация зависимости $\lg \mathrm{S}_{\mathrm{T}}=\mathrm{f}(\lg \mathrm{R})$.

Спадание спектральных амплитуд с ростом эпицентрального расстояния для каждого фиксированного периода колебаний Т слабо зависит от магнитуды землетрясения. Вместе с тем для каждой фиксированной магнитуды М с увеличением периода колебаний T в зависимости $\lg \mathrm{S}_{\mathrm{T}}=\mathrm{f}(\lg \mathrm{R})$ отмечается уменьшение наклона графика прямой линии.

Известно [Akkar, Bommer, 2010; Aptikaev, 2012; Artikov, Ibragimov, 2007; Chernov, 1989], что поведение как самих амплитуд скоростей и ускорений колебаний грунта, так и их спектральных составляющих существенно отличается для ближней зоны, соизмеримой с размером очага, и на периферии. В ближней зоне, как правило, наблюдается слабая зависимость амплитуд спектра от расстояния, в дальней зоне амплитуды скоростей колебаний грунта затухают экспоненциально.

Поиск обобщенной зависимости затухания с ростом эпицентрального расстояния $\mathrm{R}$ скоростей колебаний грунта $v$ (а также спектральных амплитуд $\mathrm{S}_{\mathrm{T}}$ на фиксированном периоде колебаний $\mathrm{T}$ ) для землетрясений различного энергетического уровня М в дальней зоне осуществлялся в виде: lgv=aMblgR+C $\left(\lg \mathrm{S}_{\mathrm{T}}=\mathrm{aM}-\mathrm{blgR}+\mathrm{C}\right)$.

Для получения очаговых спектров землетрясений различного энергетического уровня по этим зависимостям, с учетом размеров ближней зоны, рассчитывались значения спектральных амплитуд в очаговой зоне. 


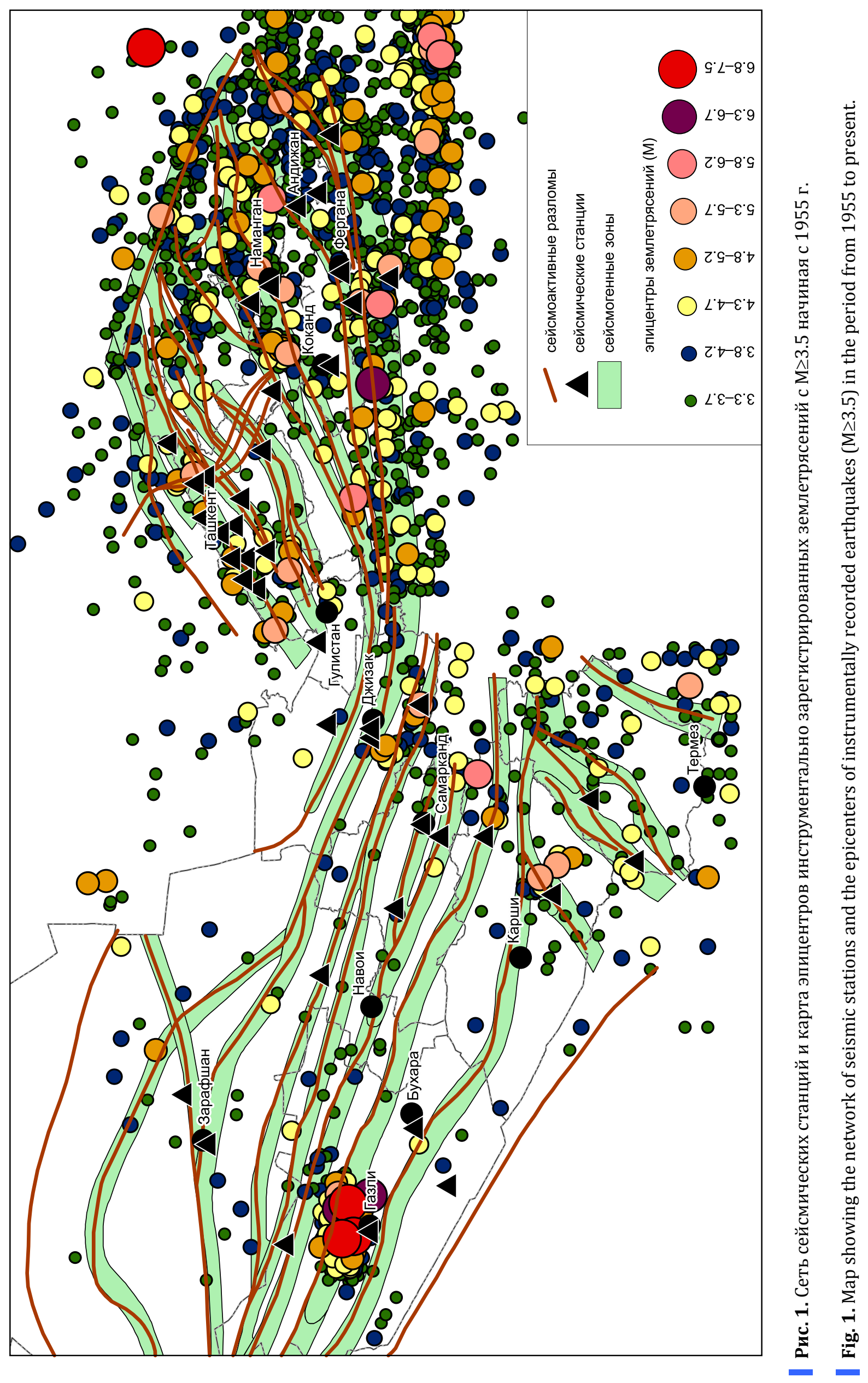



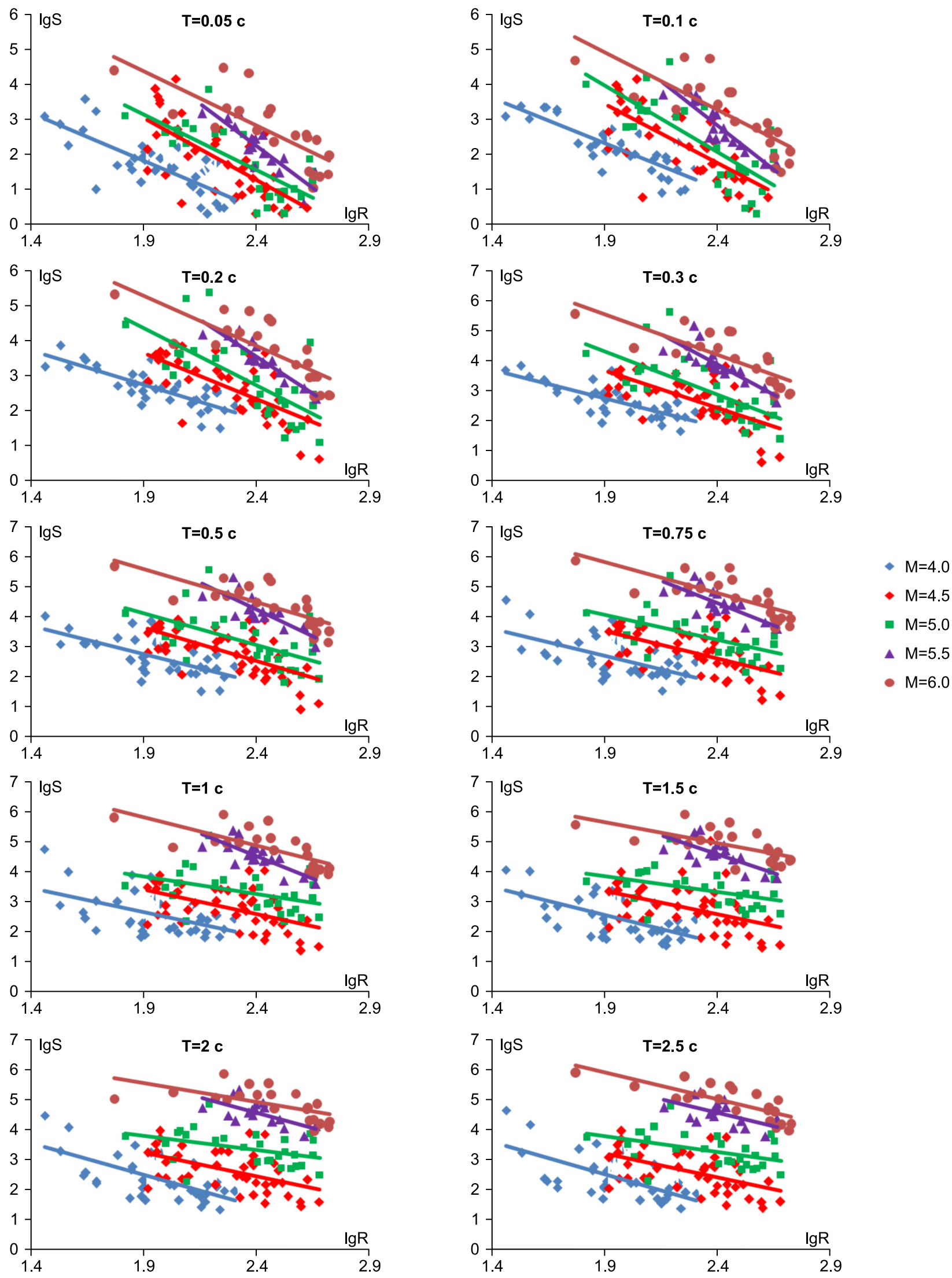

Рис. 2. Экспериментальные значения логарифма спектральных амплитуд $\lg S$ (мкрн/с), зарегистрированных на различных эпицентральных расстояниях R (км) в каждой магнитудной группе землетрясений, и их линейная аппроксимация.

Fig. 2. The experimental values of the logarithms of spectral amplitudes (lgS, micron/sec) recorded at various distances from the epicenters $(\mathrm{R}, \mathrm{km})$. The values are grouped according to the magnitudes of the earthquakes. Linear approximations are shown. 

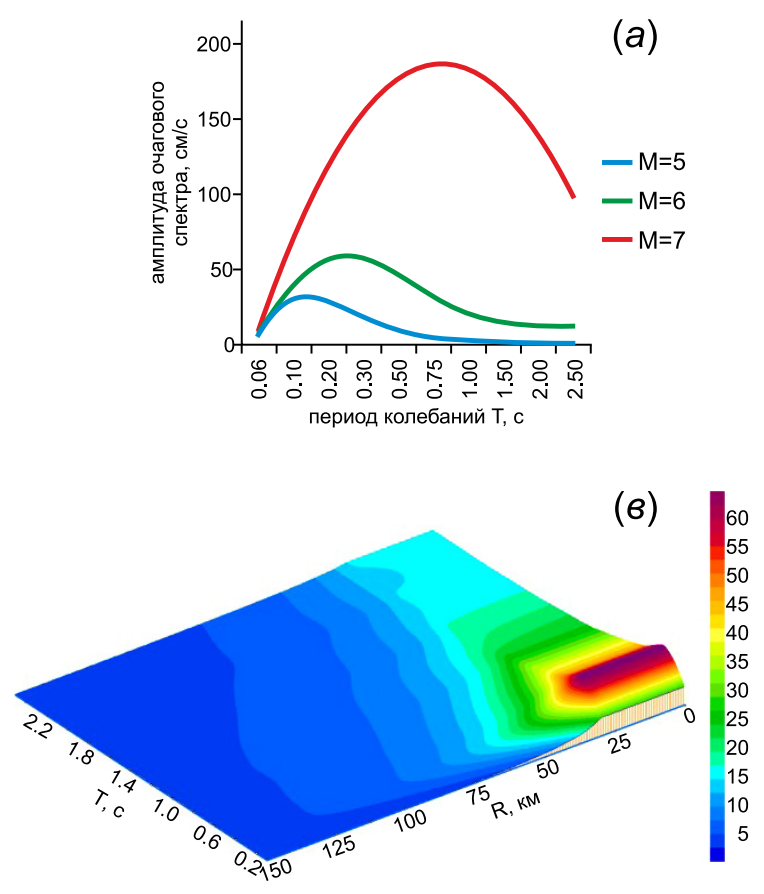

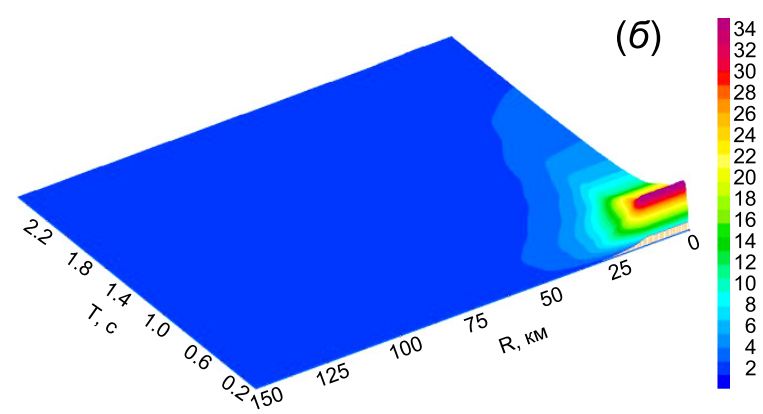

(2)

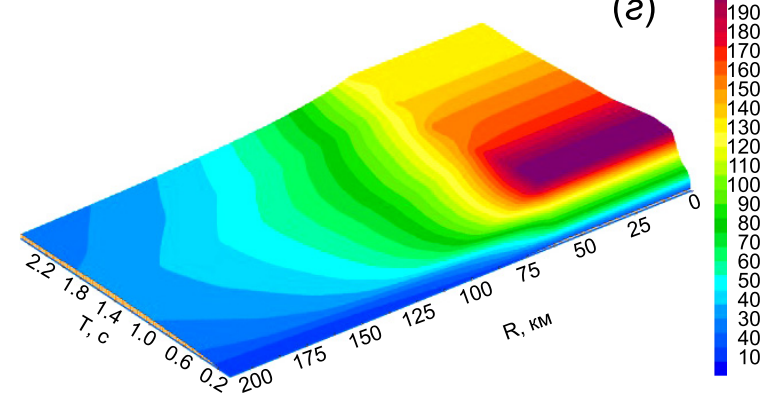

Рис. 3. Очаговые спектры землетрясений с магнитудой $\mathrm{M=5-7}(a)$ и их трансформация с удалением от источника $(6,8,2)$.

Fig. 3. Focal spectra of M 5-7 earthquakes $(a)$ and transformation of the spectra with distance from the seismic source $(6,8,2)$.

\section{3. ЗАВИСИМОСТИ ЗАТУХАНИЯ СКОРОСТЕЙ КОЛЕБАНИЙ ГРУНТА И ИХ СПЕКТРАЛЬНЫХ СОСТАВЛЯЮЩИХ С РАССТОЯНИЕМ ДЛЯ ЗЕМЛЕТРЯСЕНИЙ РАЗЛИЧНОГО ЭНЕРГЕТИЧЕСКОГО УРОВНЯ}

По всей совокупности экспериментальных данных методом наименьших квадратов была получена следующая зависимость затухания амплитуд скоростей колебаний грунта с расстоянием при землетрясениях различных магнитуд:

$$
\begin{array}{ll}
\operatorname{lgv}=\mathrm{M}-1.7 \operatorname{lgR}-3.09 & 10<\mathrm{R} \leq 100 \text { км } \\
\operatorname{lgv}=\mathrm{M}-2.35 \operatorname{lgR}-1.74 & 100 \leq \mathrm{R} \leq 500 \text { км, }
\end{array}
$$

где значение скорости $v$ дается в сантиметрах в секунду (см/с).

Зависимости затухания спектральных амплитуд скоростей колебаний грунта $S_{T}$ с удалением от источника для различных периодов сейсмических колебаний Т приведены ниже:

$\lg \mathrm{S}_{0.05}=1.021 \mathrm{M}-3.000 \lg \mathrm{R}-2.206$

$\lg \mathrm{S}_{0.1}=1.072 \mathrm{M}-3.162 \operatorname{lgR}-1.641$

$\lg \mathrm{S}_{0.2}=1.073 \mathrm{M}-2.575 \operatorname{lgR}-2.154$

$\lg \mathrm{S}_{0.3}=1.184 \mathrm{M}-2.318 \operatorname{lgR}-2.983$

$\operatorname{lgS}_{0.5}=1.260 \mathrm{M}-2.009 \operatorname{lgR}-3.902$

$\lg \mathrm{S}_{0.75}=1.316 \mathrm{M}-1.767 \operatorname{lgR}-4.650$

$\lg S_{1.0}=1.328 \mathrm{M}-1.556 \lg \mathrm{R}-5.061$

$$
\begin{aligned}
& \lg S_{1.5}=1.402 \mathrm{M}-1.399 \operatorname{lgR}-5.828 \\
& \operatorname{lgS} S_{2.0}=1.443 \mathrm{M}-1.434 \operatorname{lgR}-6.131 \\
& \lg \mathrm{S}_{2.5}=1.464 \mathrm{M}-1.557 \operatorname{lgR}-6.129,
\end{aligned}
$$

где расстояние $\mathrm{R}$ выражено в километрах, a амплитуда спектра скоростей колебаний грунта $S_{T}-$ в сантиметрах в секунду. Поскольку регистрирующие сейсмические станции располагались в различных грунтовых условиях, полученные эмпирические зависимости справедливы для средних грунтов.

Анализируя коэффициенты $a$ и $b$ в полученных зависимостях, можно отметить, что с ростом периода колебаний магнитудный коэффициент $a$ возрастает, а коэффициент затухания $b$, напротив, уменьшается, т.е. с возрастанием энергии землетрясения удельный вес низкочастотных колебаний в общем сигнале повышается, а затухание длиннопериодных волн с расстоянием происходит медленнее высокочастотных колебаний.

Экстраполируя зависимости на расстояния, характерные для размеров ближней зоны $R_{0}$ $\left(\lg R_{0}=0.301 \mathrm{M}-0.806\right)$, мы получили систему очаговых спектров скоростей для землетрясений различных магнитуд. Для примера, на рисунке $3, a$, приведены очаговые спектры скоростей колебаний грунта для землетрясений с магнитудами $\mathrm{M}=5-7$, а на рисунке $3,6-2$, показаны особенности их транс- 
формации с удалением от источника. С ростом магнитуды землетрясения очаговый спектр расширяется, увеличивается по амплитуде, а его максимум сдвигается в область низких частот. Для землетрясений больших магнитуд амплитуда низкочастотной компоненты в дальней зоне может превышать таковую в ближней зоне, в то время как высокочастотные колебания происходят в достаточно ограниченной области.

\section{4. КОЛИЧЕСТВЕННЫЕ ХАРАКТЕРИСТИКИ СЕЙСМИЧЕСКОЙ ОПАСНОСТИ ТЕРРИТОРИИ УЗБЕКИСТАНА}

Количественные оценки сейсмической опасности сейсмоактивных территорий базируются на двух взаимосвязанных моделях сейсмического процесса: модели сейсмических источников и модели сейсмического эффекта от выбранной совокупности источников землетрясений. Основу модели сейсмического эффекта составили региональные зависимости затухания скоростей колебаний грунта и их спектральных амплитуд с расстоянием для землетрясений различного энергетического уровня, приведенные выше.

В качестве модели сейсмических источников использовалась модель сейсмогенерирующих зон территории Узбекистана и сопредельных с ним территорий [Ibragimov et al., 2002]. Выделение сейсмогенерирующих зон опирается на информацию о разломах земной коры, активизированных на современном этапе геологического развития. Сейсмологическая параметризация сейсмогенных зон состояла в определении их основных долговременных сейсмологических характеристик: параметров повторяемости землетрясений различного энергетического уровня, сейсмического потенциала каждой зоны, преобладающего типа подвижки в очаге.

Для характеристики средней частоты повторения землетрясений в сейсмологической практике используются два параметра, однозначно определяющих положение прямой в фундаментальном законе Гутенберга - Рихтера [Gutenberg, Richter, 1944]. При магнитудной классификации землетрясений эта зависимость, связывающая число землетрясений различного энергетического уровня $\mathrm{N}_{\mathrm{M}} \mathrm{C}$ магнитудой М, имеет вид:

$$
\operatorname{LgN}_{M}=a-b M .
$$

В используемой авторами энергетической классификации землетрясений уравнение этой прямой обычно привязывают к энергетическому классу $\mathrm{K}_{0}=10$, и эта зависимость записывается в виде [Riznichenko, 1985]:

$$
\begin{aligned}
& \operatorname{LgN}_{\mathrm{k}}=\operatorname{LgN}_{10}-\gamma(\mathrm{K}-10), \\
& \mathrm{K}=\mathrm{LgE}, \mathrm{K} \leq \mathrm{K}_{\text {max }} .
\end{aligned}
$$

Значение $\mathrm{A}_{10}=\mathrm{N}_{10} \frac{1000}{\mathrm{ST}}$, представляющее собой среднее число землетрясений, происходящих за

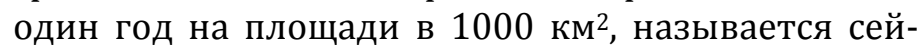
смической активностью, а значение углового коэффициента этой прямой $\gamma$ - сейсмической дробностью среды [Shebalin et al., 1991]. Здесь S - площадь $($ в км²) сейсмического источника, а Т - время (в годах) используемых сейсмологических данных.

Сейсмическая активность каждой сейсмогенерирующей зоны рассчитывалась методом распределения [Artikov et al., 2010; Riznichenko, 1985] по землетрясениям с энергетическими классами $K=9$ 13, с учетом сроков их представительной регистрации за различные периоды наблюдений. Угловой коэффициент в графике повторяемости землетрясений $\gamma$ определялся по данным за 1955-2016 гг. методом Куллдорфа [Artikov et al., 2012].

На рисунках 4 и 5 показаны карты распределения сейсмической активности $A_{10}$ и сейсмической дробности среды (параметр $\gamma$ ) для основных сейсмогенерирующих зон территории Узбекистана.

Расчет сейсмического потенциала сейсмоактивных зон $\mathrm{M}_{\max }$ осуществлялся в два этапа. На первом этапе сейсмический потенциал всех сейсмогенерирующих зон, способных вызвать ощутимые (I $\geq 6$ баллов) сотрясения, был определен исключительно сейсмологическими методами оценки $\mathrm{M}_{\max }$. На втором этапе найденные значения сейсмического потенциала были сопоставлены со значениями $\mathrm{M}_{\max }$, полученными на основе сейсмотектонических методов оценки величины максимально возможного землетрясения [Ibragimov et al., 2002]. Расчет сейсмической опасности проводился по комплексным значениям $\mathrm{M}_{\max }$, рассчитанным по совокупности сейсмологических и сейсмотектонических данных.

При оценке сейсмического потенциала на основе сейсмологических данных были использованы методы, основанные на корреляции величины максимально возможного землетрясения $\mathrm{M}_{\max }$ с сейсмической активностью сейсмоактивных зон [Riznichenko, 1985], с толщиной и линейной протяженностью сейсмоактивного слоя [Shebalin, 1971], а также метод, опирающийся на статистику максимального правдоподобия при анализе правых частей графиков повторяемости землетрясений [Pisarenko, 1991]. Применялся также метод Гумбеля, основанный на статистике экстремальных значений, и другие методы [Artikov et al., 2012]. Комплексный вариант карты $\mathrm{M}_{\max }$ на основе сейсмологических данных показан на рисунке 6. Оценки сейсмического потенциала сейсмогенных зон на 


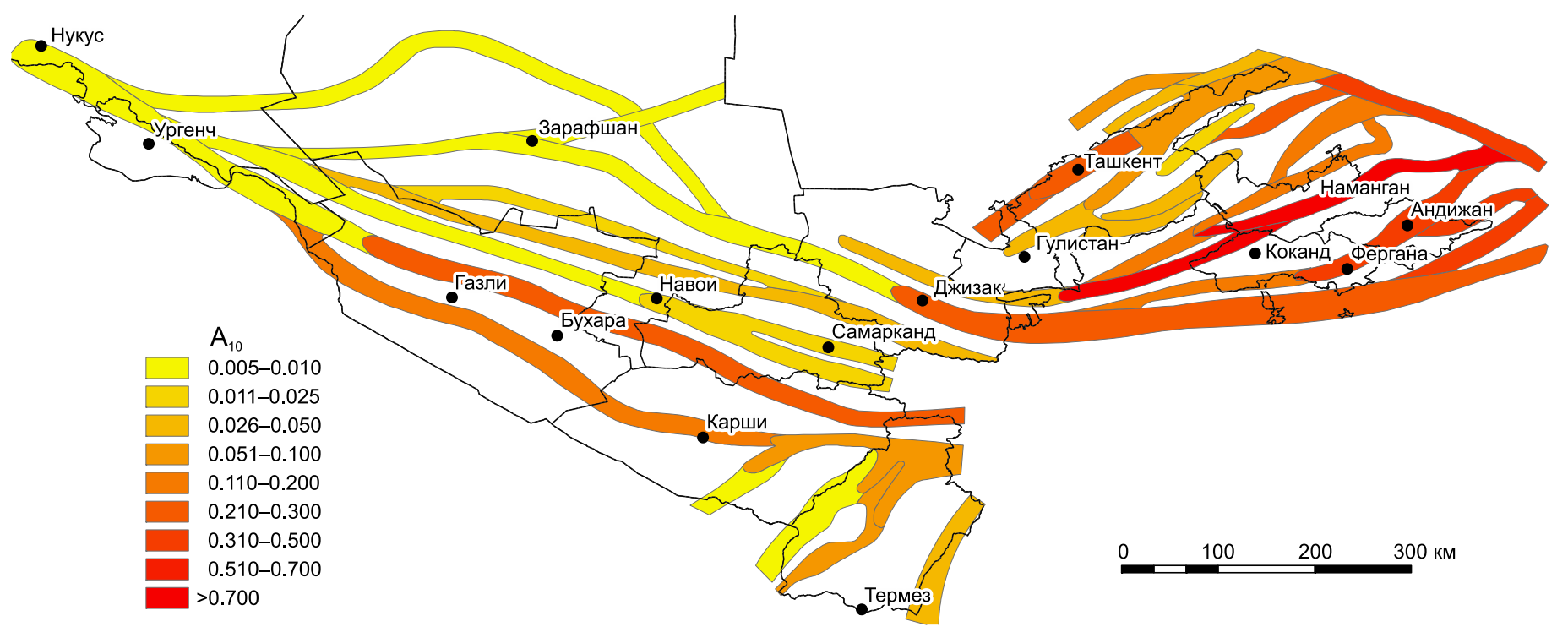

Рис. 4. Сейсмическая активность сейсмогенерирующих зон территории Узбекистана.

Fig. 4. Seismic activity of seismogenic zones in the territory of Uzbekistan.

основе сейсмотектонических данных приведены в [Ibragimov et al., 2002].

Расчет сейсмической опасности проводился на базе программного комплекса «SEISMHAZARD_UZ», разработанного в лаборатории региональной сейсмичности и сейсмического районирования Института сейсмологии АН РУз [Ibragimov, Ibragimova, 2016].

На первом этапе в каждом узле сетки для каждого фиксированного значения амплитуды скоро- сти колебаний грунта $\left(\mathrm{V}_{\max }=1-300 \mathrm{~cm} / \mathrm{c}\right)$ с дискретностью $\Delta v_{\max }=0.1 \mathrm{~cm} /$ б была рассчитана частота повторения таких сотрясений во времени. В основе расчета частоты повторения сотрясений с заданной интенсивностью $v_{\max } \geq v_{0}$ лежит интеграл:

$$
\mathrm{B}_{v}=\int_{\mathrm{V}} \mathrm{N}_{\Sigma} d \mathrm{~V}
$$

где $N_{\Sigma}$ - отнесенное к единице времени и объема ожидаемое число землетрясений, очаги которых

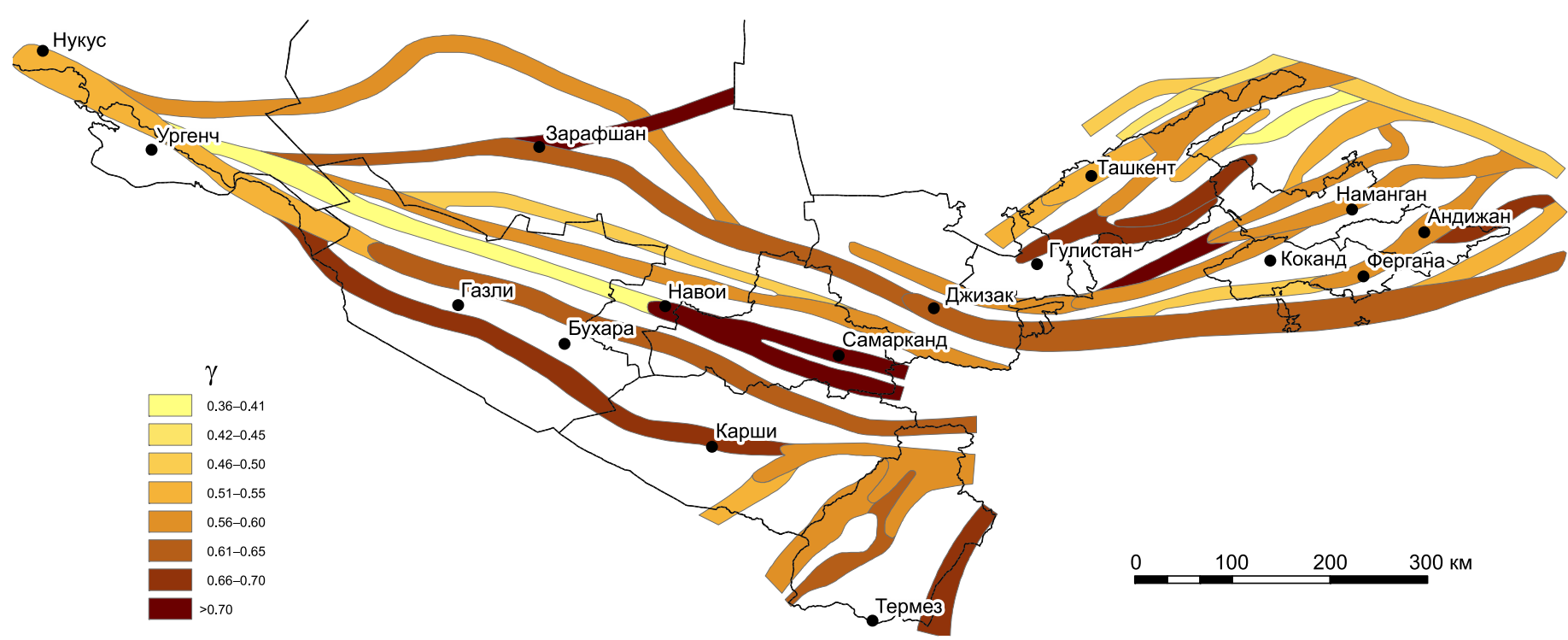

| Рис. 5. Сейсмическая дробность сейсмогенерирующих зон территории Узбекистана.

Fig. 5. Seismic fragmentation of seismogenic zones in the territory of Uzbekistan. 


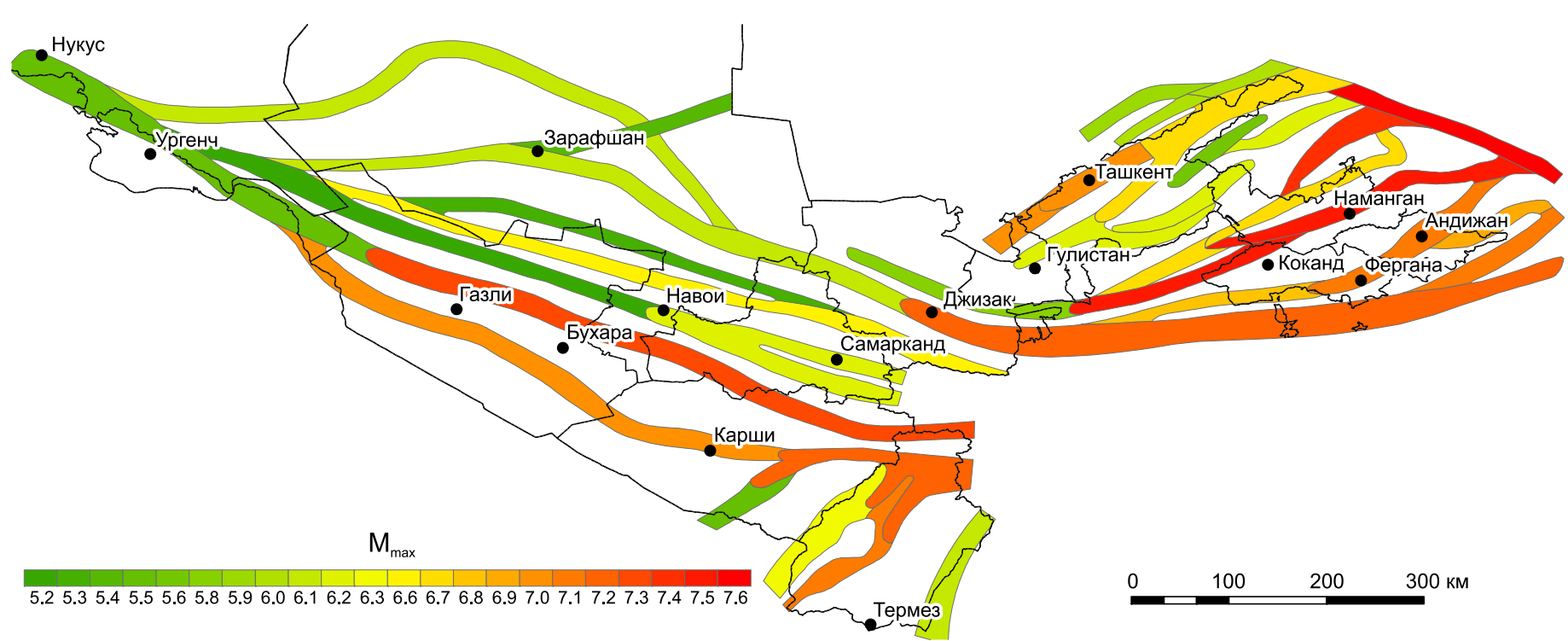

Рис. 6. Сейсмический потенциал сейсмогенных зон территории Узбекистана по комплексу сейсмологических методов.

Fig. 6. Seismic potential of the seismogenic zones in Uzbekistan, according to the data obtained by seismological methods.

расположены в элементарных объемах $d V$, способных вызвать в пункте наблюдения колебание грунта с амплитудой скоростей $\mathrm{V}_{\max } \geq \mathrm{v}_{0}$ [Artikov et al., 2012; Ibragimov, Ibragimova, 2016; Riznichenko, 1985].

На втором этапе выделялись зоны максимальной интенсивности сейсмического воздействия с периодом повторяемости один раз в $\mathrm{T}=500, \mathrm{~T}=1000$, $\mathrm{T}=2500$ и $\mathrm{T}=5000$ лет. Эти зоны являются областями, в которых вероятность непревышения сейсмического воздействия в течение промежутка времени $\tau=50$ лет составляет соответственно $\mathrm{P}=0.90$, $\mathrm{P}=0.95, \mathrm{P}=0.98$ и $\mathrm{P}=0.99$.

Аналогичная процедура была проделана для амплитуд спектральных составляющих $\mathrm{S}_{\mathrm{T}}$ на заданном периоде сейсмических колебаний T.

Единичный градусный квадрат географической сетки разбивался на 16 частей по широте и долготе, т.е. на 256 ячеек, которым приписывались значения входных параметров (сейсмическая активность $A_{10}$, сейсмическая дробность $\gamma$, величина сейсмического потенциала $\left.\mathrm{M}_{\max }\right)$. C такой же детальностью были получены результирующие оценки сейсмической опасности.

Серия карт, выражающих сейсмическую опасность территории Узбекистана в значениях максимальных скоростей колебаний для различных вероятностей (P=0.90; $\mathrm{P}=0.95 ; \mathrm{P}=0.98$ и $\mathrm{P}=0.99)$ непревышения уровня сейсмического воздействия в течение 50 лет, приведена на рисунке 7.

На рисунках 8-11 приведены карты сейсмической опасности территории Узбекистана в значениях спектральных амплитуд скоростей колебаний грунта для периодов колебаний Т=0.1 с, Т=0.3 с,
$\mathrm{T}=0.5$ с и $\mathrm{T}=1$ с для различных вероятностей $\mathrm{P}$ $(\mathrm{P}=0.90 ; \mathrm{P}=0.95$ и $\mathrm{P}=0.98)$ непревышения интенсивности сейсмического воздействия в течение 50 лет.

На рисунке 12 приведены «сотрясаемостные спектры» [Riznichenko, Seiduzova, 1984] некоторых городов, расположенных на территории Узбекистана. Эти спектры показывают пороговые значения спектральных амплитуд, которые на средних грунтах с заданной вероятностью $\mathrm{P}(\mathrm{P}=0.90 ; \mathrm{P}=0.95$ и $\mathrm{P}=0.98)$ не будут превышены в течение 50 лет.

\section{5. ОБСУЖДЕНИЕ ПОЛУЧЕННЫХ РЕЗУЛЬТАТОВ}

Как это видно из рисунка 7, отмечается резкая дифференциация территории по значениям $v_{\text {мах. }}$ При этом наибольшие значения скоростей ( $\mathrm{v}_{\mathrm{max}}=$ =100-120 см/сек для $\mathrm{P}=0.99)$ концентрируются в достаточно узких зонах, генерирующих землетрясения соответствующей интенсивности. Наибольшими значениями скоростей колебаний грунта характеризуются три области. На западе это область, совпадающая с западным простиранием ЮжноТянь-Шаньской сейсмоактивной зоны и переходящая на юге в область, контролируемую сейсмической активностью Гисаро-Кокшаальского разлома, в пределах которых произошли Газлийские землетрясения 1976-1984 гг. и Каратагское землетрясение 1907 г. с $\mathrm{M} \geq 7$. В Восточном Узбекистане наибольшими значениями скоростей колебаний грунта характеризуются Северо-Ферганская и Андижанская сейсмоактивные зоны. Здесь на отдельных участках прогнозные значения амплитуд скоро- 


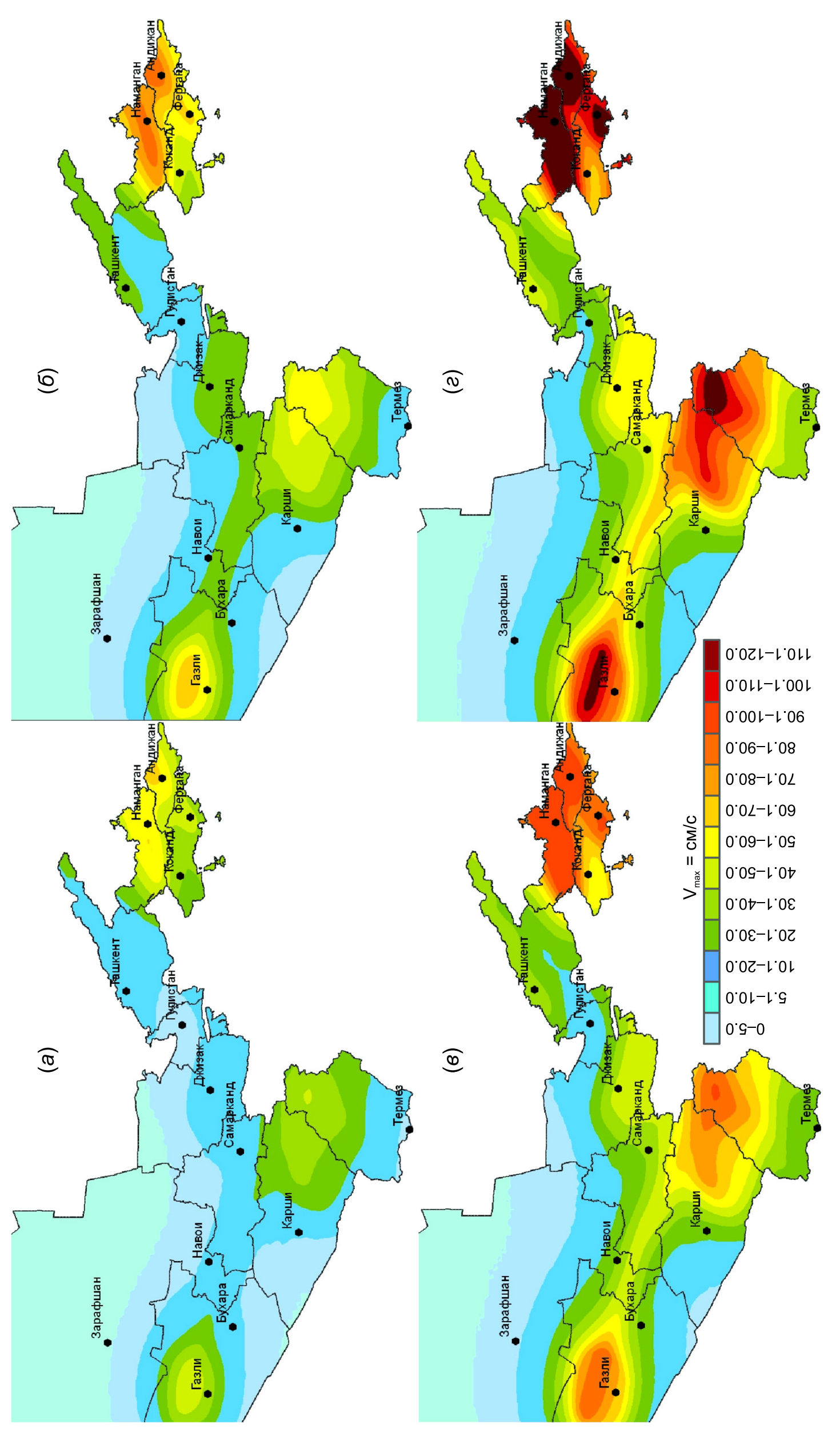

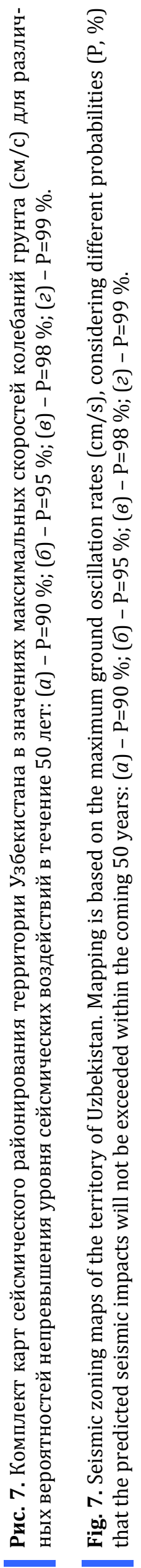



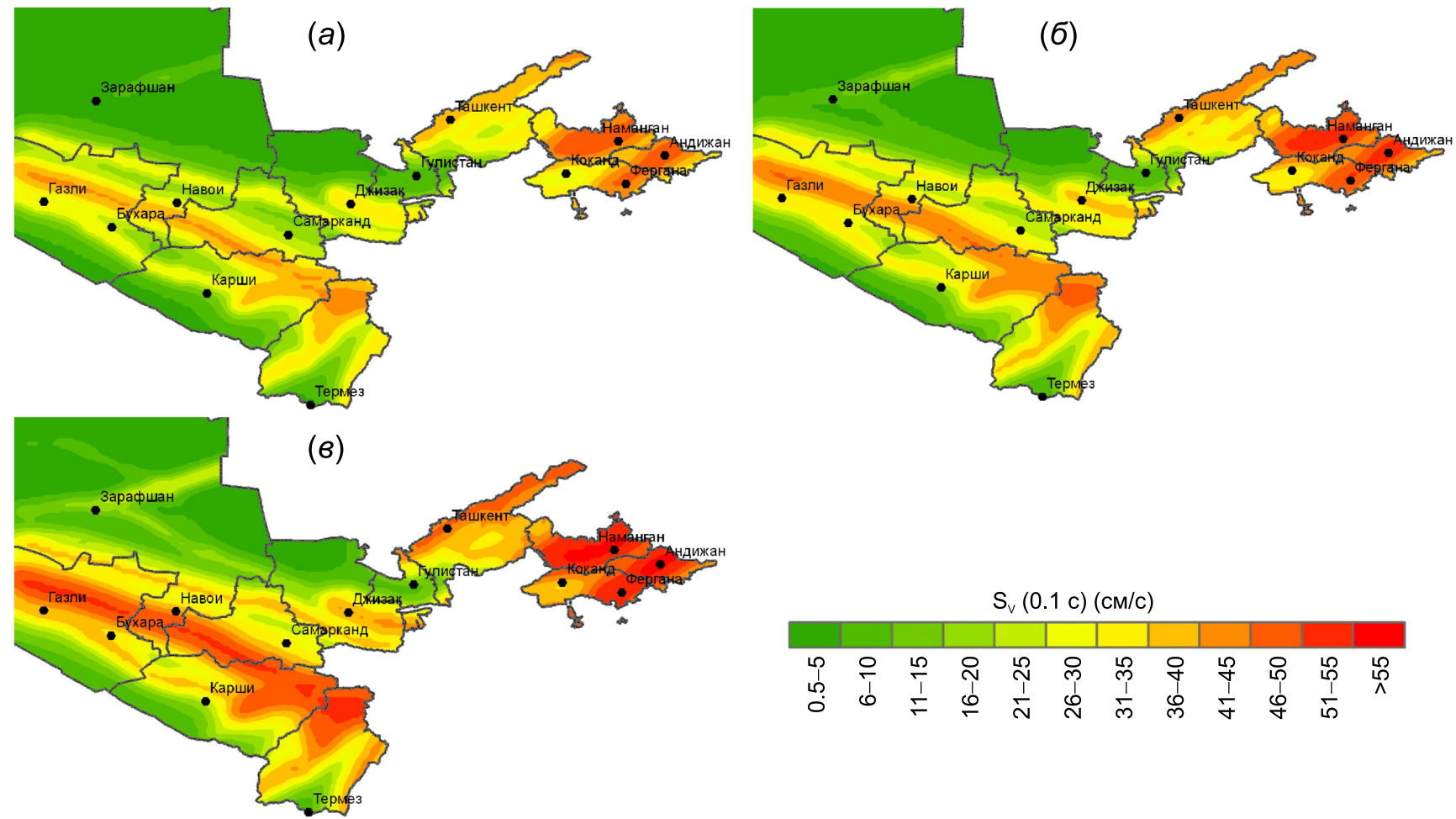

Рис. 8. Вероятностные карты сейсмической опасности территории Узбекистана в спектральных амплитудах скоростей колебаний грунта для периода колебаний T=0.1 c: $(a)$ - P=0.90; (б) - P=0.95; ( $)$ - P=0.98.

Fig. 8. Maps of Uzbekistan showing probable seismic hazard according to the spectral amplitudes of the ground oscillation rates for the oscillation period $\mathrm{T}=0.1 \mathrm{~s}:(a)-\mathrm{P}=0.90 ;($ ) $)$ - $\mathrm{P}=0.95 ;(b)-\mathrm{P}=0.98$.
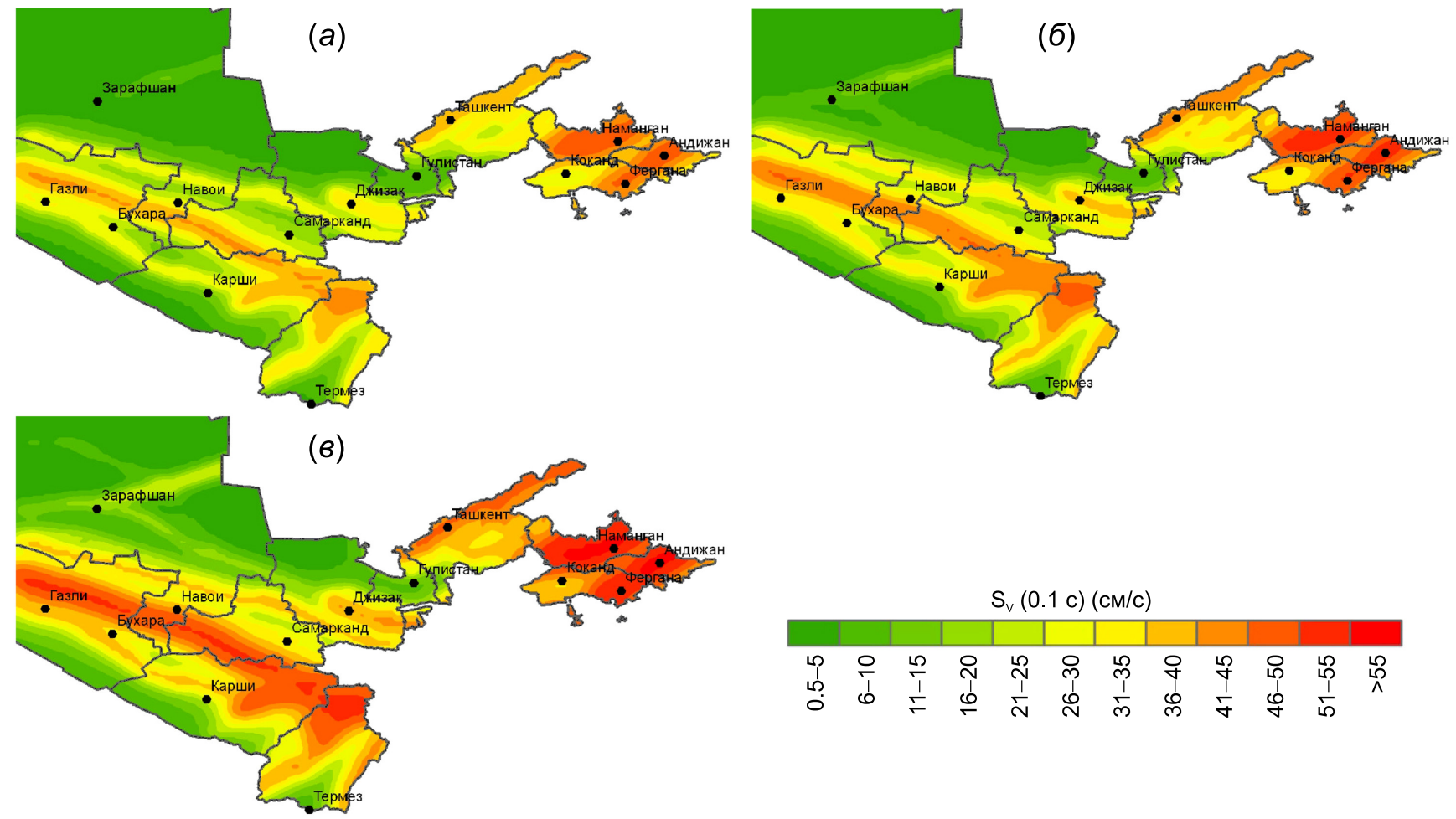

Рис.9. Вероятностные карты сейсмической опасности территории Узбекистана в спектральных амплитудах скоростей колебаний грунта для периода колебаний T=0.3 c: $(a)$ - $\mathrm{P}=0.90$; (б) - $\mathrm{P}=0.95$; $(8)$ - $\mathrm{P}=0.98$.

Fig. 9. Maps of Uzbekistan showing probable seismic hazard according to the spectral amplitudes of the ground oscillation rates for the oscillation period $\mathrm{T}=0.3 \mathrm{~s}:(a)-\mathrm{P}=0.90 ;(\sigma)-\mathrm{P}=0.95 ;(\varepsilon)-\mathrm{P}=0.98$. 

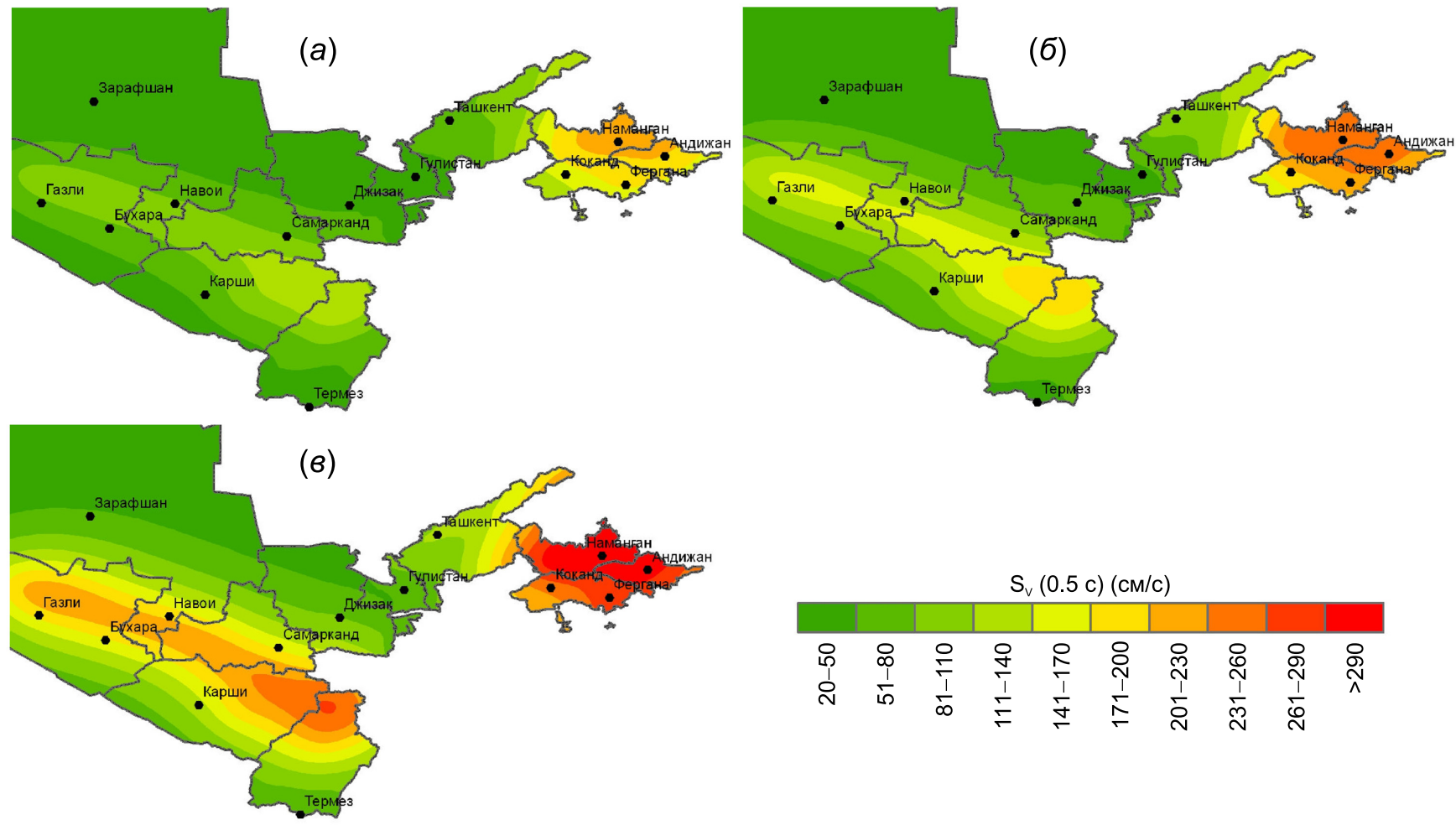

Рис. 10. Вероятностные карты сейсмической опасности территории Узбекистана в спектральных амплитудах скоростей колебаний грунта для периода колебаний Т=0.5 c: $(a)$ - P=0.90; (б) - P=0.95; (в) - P=0.98.

Fig. 10. Maps of Uzbekistan showing probable seismic hazard according to the spectral amplitudes of the ground oscillation rates for the oscillation period $\mathrm{T}=0.5 \mathrm{~s}:(a)-\mathrm{P}=0.90 ;($ б $)-\mathrm{P}=0.95 ;($ ) $)-\mathrm{P}=0.98$.
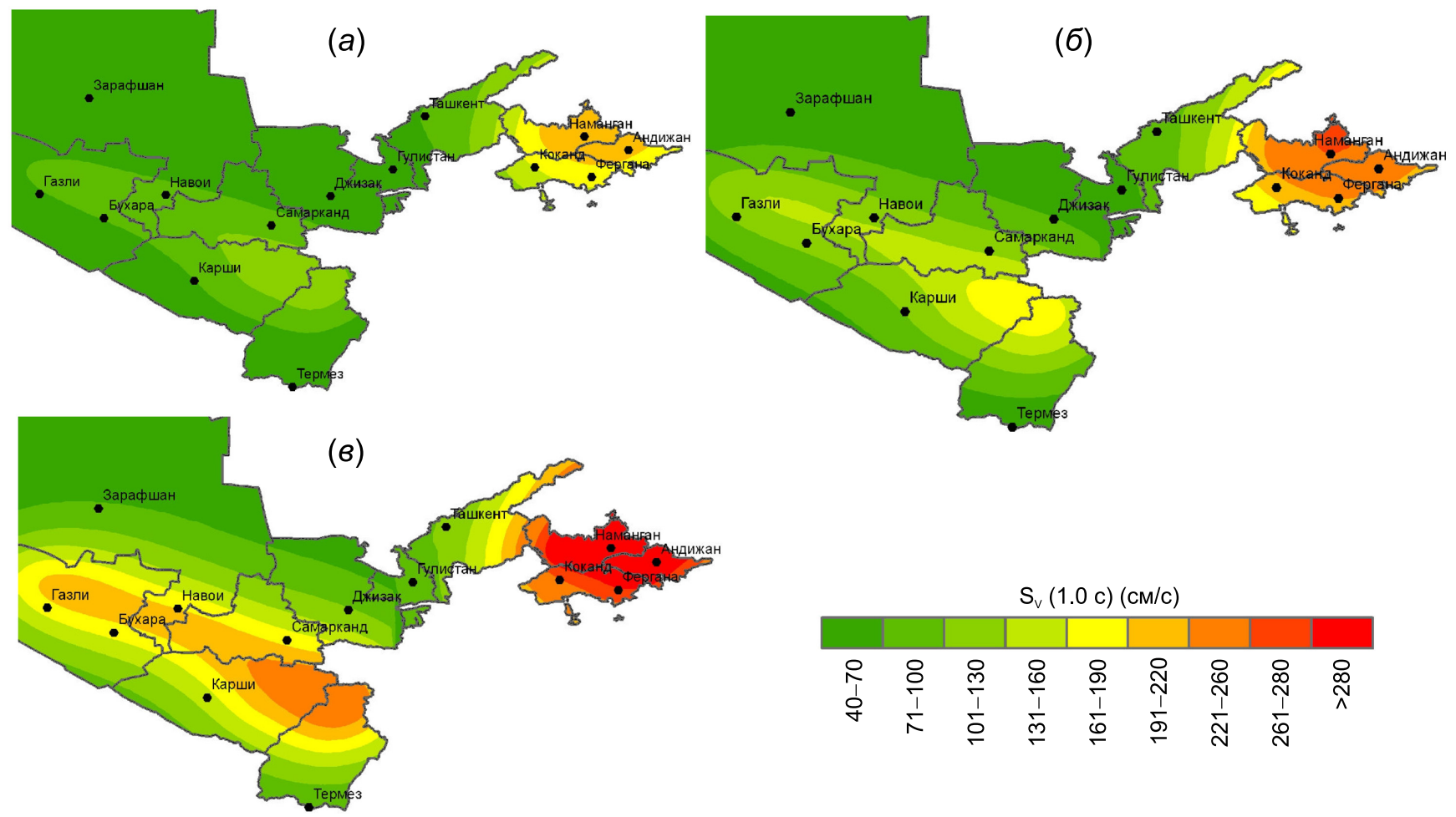

Рис. 11. Вероятностные карты сейсмической опасности территории Узбекистана в спектральных амплитудах скоростей колебаний грунта для периода колебаний Т=1 с: $(a)-\mathrm{P}=0.90$; (б) - $\mathrm{P}=0.95$; $(8)-\mathrm{P}=0.98$.

Fig. 11. Maps of Uzbekistan showing probable seismic hazard according to the spectral amplitudes of the ground oscillation rates for the oscillation period $\mathrm{T}=1 \mathrm{~s}:(a)-\mathrm{P}=0.90 ;(6)-\mathrm{P}=0.95 ;(\beta)-\mathrm{P}=0.98$. 

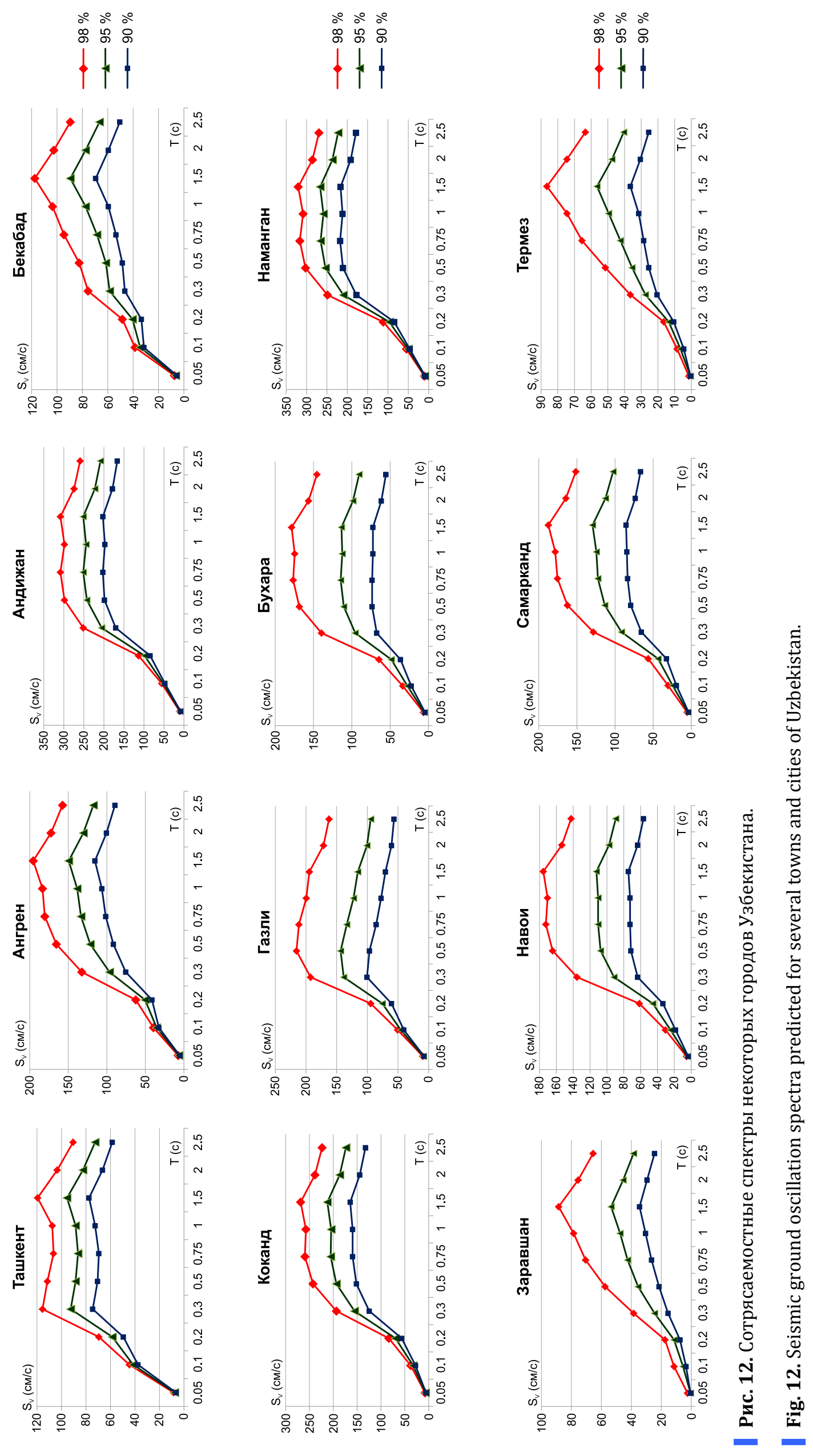
стей колебаний грунта $v_{\text {мах }}$ могут превышать величины $\mathrm{V}_{\text {мах }}=100 \mathrm{~cm} / \mathrm{c}$. В Приташкентском районе, контролируемом сейсмической активностью одноименной флексурно-разрывной зоны, величины максимальных скоростей колебаний грунта не должны в течение 50 лет превосходить значения $\mathrm{v}_{\text {мах }}=50 \mathrm{~cm} /$ с с вероятностью $\mathrm{P}=0.99$.

Анализируя карты сейсмической опасности территории Узбекистана в спектральных амплитудах скоростей сейсмических колебаний, можно отметить, что для периода колебаний $\mathrm{T}=0.1 \mathrm{c}$ они достаточно структурированы и сохраняют в изолиниях конфигурацию сейсмических источников. Но, в отличие от карт, выражающих сейсмическую опасность в спектральных амплитудах ускорений колебаний грунта [Artikov, Ibragimov, 2007; Artikov et al., 2012], с увеличением периода колебаний Т в построенных картах конфигурация изолиний существенно отклоняется от конфигурации сейсмических источников. Это связано с более медленным затуханием низкочастотных колебаний скоростей колебаний грунта по сравнению с аналогичными параметрами сейсмических ускорений, поэтому для периодов колебаний $\mathrm{T}=0.5$ с и $\mathrm{T}=1$ с большие значения спектральных амплитуд в высокоэнергетичных сейсмогенерирующих зонах Ферганской межгорной впадины прослеживаются на существенном удалении от сейсмогенных зон.

Сопоставляя между собой «сотрясаемостные спектры» городов Приташкентского района, можно отметить, что они отличаются не только по величине, но и по характеру расположения максимумов. На «сотрясаемостном спектре» для Ташкента наблюдаются два отчетливых, соизмеримых по величине, максимума на периодах колебаний $\mathrm{T}=0.3$ с и $\mathrm{T}=1.5-2.0$ с. Первый высокочастотный максимум связан с проявлением локальных землетрясений, происходящих непосредственно в пределах Приташкентской флексурно-разрывной зоны (таких, как Ташкентское землетрясение 1966 г. с M=5.3, Назарбекское 1980 г. с M=5.2 и др.). Второй максимум для периода колебаний T=1.5-2.0 с свидетельствует о том, что низкочастотные колебания от транзитных землетрясений могут иметь также достаточно высокую амплитуду, как это было при далеком, но очень сильном Чаткальском землетрясении 1946 г. с М=7.5, которое произошло на расстоянии порядка 200 км от Ташкента. Макросейсмический эффект от каждого из упомянутых здесь землетрясений был примерно одинаковый и составлял 7-8 баллов по шкале MSK-64. В случае близких землетрясений отмечались высокочастотные колебания, а при удаленных землетрясениях - практически такие же по амплитуде низкочастотные колебания.

Для городов Ферганской межгорной впадины «сотрясаемостные спектры» достаточно похожи по форме, но существенно различаются по амплитуде. Сейсмическая опасность города Коканда ниже, чем городов Андижана и Намангана, что достаточно отчетливо видно и на амплитудах спектров. Вместе с тем соизмеримые по величине значения спектральных амплитуд на периодах колебаний $\mathrm{T}=0.5-$ 1.5 с говорят о том, что каждый из этих населенных пунктов в одинаковой степени подвержен воздействию как локальных, так и сильных транзитных землетрясений.

Города Зарафшан и Термез, расположенные в Западном Узбекистане, находятся на значительном удалении от сейсмоактивных зон, и поэтому максимальные значения спектра для этих городов располагаются в длиннопериодной области, поскольку обязаны своим образованием отдаленным транзитным землетрясениям. Максимум спектра для города Газли, расположенного непосредственно в высокопотенциальной Южно-Тяньшаньской сейсмогенерирующей зоне, приходится на период колебаний $\mathrm{T}=0.5$ с, что согласуется с положением максимума очагового спектра землетрясений с магнитудой $\mathrm{M} \geq 7$.

\section{6. ЗАКЛЮЧЕНИЕ}

Таким образом, результаты проведенных исследований сводятся к следующему.

1. Получены региональные зависимости затухания с расстоянием скоростей колебаний грунта и их спектральных амплитуд для землетрясений различного энергетического уровня, рассчитаны очаговые спектры землетрясений.

2. Проведена вероятностная оценка сейсмической опасности территории Узбекистана в показателях максимальных значений скоростей колебаний грунта и их спектральных амплитудах.

3. Для ряда населенных пунктов построена система «сотрясаемостных спектров», характеризующих максимальный уровень сейсмического воздействия на фиксированной частоте сейсмического сигнала, который с различной вероятностью не будет превышен в течение 50 лет.

\section{7. ЛИТЕРАTУРA / REFERENCES}

Akkar S., Bommer J.J., 2010. Empirical equations for the prediction of PGA, PGV and spectral accelerations in Europe, the Mediterranean and the Middle East. Seismological Research Letters 81 (2), 195-206. https://doi.org/10.1785/ gssrl.81.2.195. 
Aptikaev F.F., 2012. Instrumental Scale of Seismic Intensity. Nauka i Obrazovanie, Moscow, 176 p. (in Russian) [Anmuкаев Ф.Ф. Инструментальная шкала сейсмической интенсивности. Москва: Наука и образование, 2012. 176 c.].

Artikov T.U., Ibragimov R.S., 2007. Spectral ground oscillation rates of the territory of Eastern Uzbekistan. Geology and Mineral Resources (1), 45-49 (in Russian) [Артиков Т.У., Ибрагимов P.С. Спектральная сотрясаемость территории Восточного Узбекистана // Геология и минеральные ресурсы. 2007. № 1. С. 45-49].

Artikov T.U., Ibragimov R.S., Ibragimova T.L., Mirzaev M.A., 2010. Seismological characteristics of seismogenic zones in the territory of Uzbekistan. Geology and Mineral Resources (2), 24-30 (in Russian) [Артиков Т.У., Ибрагимов Р.C., Ибрагимова Т.Л., Мирзаев М.A. Сейсмологические характеристики сейсмогенных зон территории Узбекистана // Геология и минеральные ресурсы. 2010. № 2. С. 24-30].

Artikov T.U., Ibragimov R.S., Ibragimova T.L., Mirzaev M.A., 2018. Methodology for constructing a new set of the general seismic zoning maps of the territory of Uzbekistan OSR-2017. Georisk (2), 6-24 (in Russian) [Артиков Т.У., Ибрагимов Р.С., Ибрагимова Т.Л., Мирзаев М.А. Методология построения нового комплекса карт общего сейсмического районирования территории Узбекистана ОСР-2017 // Геориск. 2018. № 2. С. 6-24].

Artikov T.U., Ibragimov R.S., Ziyaudinov F.F., 2012. Seismic Hazard of the Territory of Uzbekistan. Fan, Tashkent, 254 p. (in Russian) [Артиков Т.У., Ибрагимов Р.С., Зияудинов Ф.Ф. Сейсмическая опасность территории Узбекистана. Ташкент: Фан, 2012. 254 с.].

Chernov Yu.K., 1989. Strong Ground Motion and Quantitative Assessment of Seismic Hazard of the Territories. Fan, Tashkent, 295 p. (in Russian) [Чернов Ю.К. Сильные движения грунта и количественная оценка сейсмической опасности территорий. Ташкент: Фан, 1989. 295 с. ].

Drennov A.F., Dzhurik V.I., Serebrennikov S.P., Bryzhak E.V., Drennova N.N., 2015. The basic parameters of acceleration spectra for M>5 earthquakes in the Baikal rift zone. Russian Geology and Geophysics 56 (5), 773-781. https:// doi.org/10.1016/j.rgg.2015.04.008.

Gutenberg B., Richter C.F., 1944. Frequency of earthquakes in California. Bulletin of the Seismological Society of America $34(4), 185-188$.

Ibragimov R.N., Nurmatov U.O., Ibragimov O.R., 2002. Seismotectonic method of seismic hazard assessment and seismic zoning issues. In: Seismic zoning and earthquake prediction in Uzbekistan. Hydroingeo, Tashkent, p. 59-74 (in Russian] [Ибрагимов P.Н., Нурматов У.О., Ибрагимов О.Р. Сейсмотектонический метод оценки сейсмической опасности и вопросы сейсмического районирования // Сейсмическое районирование и прогноз землетрясений в Узбекистане. Ташкент: Гидроингео, 2002. С. 59-74].

Ibragimov R.S., Ibragimova T.L., 2016. Program of Seismic Hazard Assessment of the Territory of Uzbekistan. State Patent Office of the Republic of Uzbekistan. Certificate No. DGU 04041. 28.10.2016 (in Russian) [Ибрагимов P.С., Ибрагимова Т.Л. Программа оценки сейсмической опасности территории Узбекистана. Государственное патентное ведомство РУз. Свидетельство № DGU 04041. 28.10.2016].

Lindholm C., Abdrahmatov K., Mihailova N., Ischuk A., 2014. Earthquake Hazard and Risk Assessment in Kyrgyzstan and Tajikistan with Cooperation to Afghanistan and Uzbekistan 2011-2014. Norwegian Ministry of Foreign Affairs Press, Oslo, 49 p.

Mikhailova N.N., Neverova N.P., Kalmykova N.A., 1999. Energy and magnitude characteristics of earthquakes in seismic observations on the Northern Tien Shan. In: Earthquakes of Northern Eurasia in 1993. NIA Priroda, Moscow, p. 60-64 (in Russian) [Михайлова Н.Н., Неверова Н.П., Калмыкова Н.А. Энергетические и магнитудные характеристики землетрясений в практике сейсмических наблюдений на Северном Тянь-Шане // Землетрясения Северной Евразии в 1993 г. М.: НИА Природа, 1999. С. 60-64].

Pisarenko V.F., 1991. Statistical estimation of the maximum possible earthquakes. Izvestia AN SSSR, Seriya Fizika Zemli (9), 38-47 (in Russian) [Писаренко В.Ф. Статистическое оценивание максимально возможных землетрясений // Известия АН СССР, серия Физика Земли. 1991. № 9. С. 38-47].

Riznichenko Yu.V., 1985. Selected Works. Problems of Seismology. Publishing House of the USSR Acad. Sci., Moscow 408 p. (in Russian) [Ризниченко Ю.В. Избранные труды. Проблемы сейсмологии. М.: Изд-во АН СССР, 408 с. ].

Riznichenko Yu.V., Seiduzova S.S., 1984. Spectrum-Time Characteristics of Seismic Hazard. Publishing House of the USSR Acad. Sci., Moscow, 180 p. (in Russian) [Ризниченко Ю.В., Сейдузова С.С. Спектрально-временная характеристика сейсмической опасности. Москва: Изд-во АН СССР, 1984. 180 с.].

Shebalin N.V., 1971. About the limiting and maximum magnitudes of earthquakes. Izvestiya AN SSSR, Seriya Fizika Zemli (6), 12-20 (in Russian) [Шебалин Н.B. О предельной магнитуде и предельной балльности землетрясений // Известия АН СССР, серия Физика Земли. 1971. № 6. С. 12-20].

Shebalin N.V., Arefiev S.S., Vasiliev V.Yu., Tatevosyan R.E., 1991. From the seismicity of areas to the structure of seismicity. Izvestiya AN SSSR, Seriya Fizika Zemli (9), 20-28 (in Russian) [Шебалин Н.В., Арефьев С.С., Васильев В.Ю., Татевосян Р.Э. От сейсмичности площадей к структуре сейсмичности // Известия АН СССР, серия Физика Земли. 1991. № 9. С. 20-28].

Ullah S., Bindi D., Pilz M., Danciu L., Weatherill G., Zuccolo E., Ischuk A., Mikhailova N., Abdrakhmatov K., Parolai S., 2015. Probabilistic seismic hazard assessment for Central Asia. Annals of Geophysics 58 (1), S0103. https://doi.org/ 10.4401/ag-6687. 


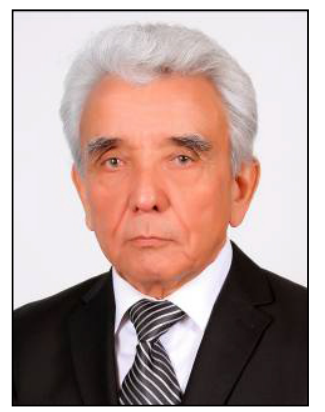

Турдали Усманалиевич Артиков, докт. физ.-мат. наук, профессор, заведующий лабораторией Институт сейсмологии им. Г.А. Мавлянова Академии наук Республики Узбекистан 100128, Ташкент, ул. Зульфияхонум, 3, Узбекистан

凶e-mail: artikovtu@mail.ru

Turdali U. Artikov, Doctor of Physics and Mathematics, Professor, Head of Laboratory G.A. Mavlyanov Institute of Seismology, Academy of Sciences of the Republic of Uzbekistan 3 Zulfiyakhonum street, Tashkent 100128, Uzbekistan

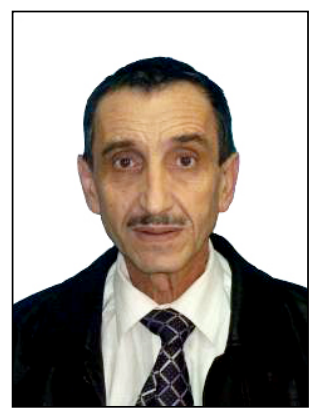

Роман Соломонович Ибрагимов, докт. физ.-мат. наук, в.н.с.

Институт сейсмологии им. Г.А. Мавлянова Академии наук Республики Узбекистан 100128, Ташкент, ул. Зульфияхонум, 3, Узбекистан

e-mail: ibrroma@yandex.ru

Roman S. Ibragimov, Doctor of Physics and Mathematics, Lead Researcher

G.A. Mavlyanov Institute of Seismology, Academy of Sciences of the Republic of Uzbekistan 3 Zulfiyakhonum street, Tashkent 100128, Uzbekistan

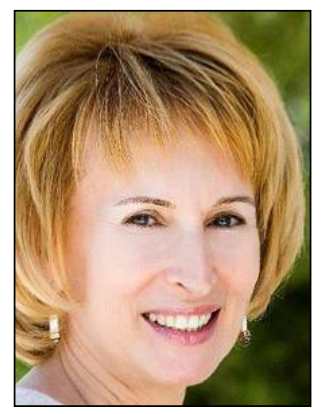

Татьяна Людвиговна Ибрагимова, докт. физ.-мат. наук, в.н.с.

Институт сейсмологии им. Г.А. Мавлянова Академии наук Республики Узбекистан 100128, Ташкент, ул. Зульфияхонум, 3, Узбекистан

e-mail: tam.anay@yahoo.com

Tatiana L. Ibragimova, Doctor of Physics and Mathematics, Lead Researcher

G.A. Mavlyanov Institute of Seismology, Academy of Sciences of the Republic of Uzbekistan 3 Zulfiyakhonum street, Tashkent 100128, Uzbekistan

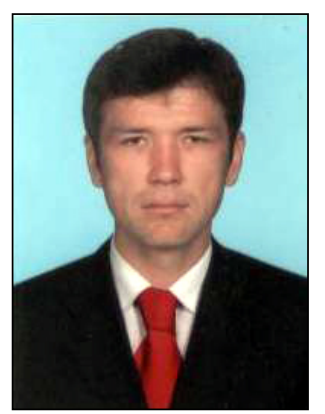

Кахрамон Исраилович Кучкаров, н.с.

Институт сейсмологии им. Г.А. Мавлянова Академии наук Республики Узбекистан 100128, Ташкент, ул. Зульфияхонум, 3, Узбекистан

e-mail: geofizik_1987@mail.ru

Kakhramon I. Kuchkarov, Researcher

G.A. Mavlyanov Institute of Seismology, Academy of Sciences of the Republic of Uzbekistan 3 Zulfiyakhonum street, Tashkent 100128, Uzbekistan

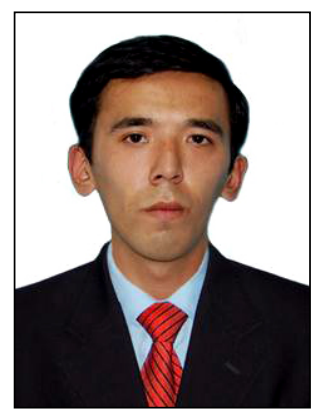

Муроджон Абдурахимджанович Мирзаев, н.с.

Институт сейсмологии им. Г.А. Мавлянова Академии наук Республики Узбекистан 100128, Ташкент, ул. Зульфияхонум, 3, Узбекистан

e-mail: mumirzaev@gmail.com

Murodzhon A. Mirzaev, Researcher

G.A. Mavlyanov Institute of Seismology, Academy of Sciences of the Republic of Uzbekistan 3 Zulfiyakhonum street, Tashkent 100128, Uzbekistan 